\title{
À luz da Ciência na Educação Infantil: Desafiando a imaginação infantil a desvendar fenômenos ópticos ${ }^{+}$
}

\author{
Guilherme Frederico Marranghello ${ }^{1}$ \\ Márcia Maria Lucchese ${ }^{1}$ \\ Universidade Federal do Pampa - Campus Bagé \\ Bagé - RS \\ Angela Maria Hartmann ${ }^{1}$ \\ Universidade Federal do Pampa - Campus Caçapava do Sul \\ Caçapava do Sul - RS
}

\section{Resumo}

Este trabalho apresenta uma análise da visitação de crianças de 4 a 6 anos à exposição À Luz da Ciência na Educação Infantil, promovida pela Universidade Federal do Pampa, a partir de uma proposta de divulgação e popularização da ciência sobre a temática Luz. A proposta fez parte das comemorações do Ano Internacional da Luz (2015), tendo recebido fomento do Conselho Nacional de Desenvolvimento Científico e Tecnológico (CNPq) para sua realização em dois campi: Bagé (em 2016) e Caçapava do Sul (em 2017). Descrevemos neste trabalho as treze estações do circuito da exposição, analisando, em seguida, como as crianças, acompanhadas por suas professoras e monitores da universidade, interagiram com os experimentos e artefatos, bem como sua capacidade de expressar conceitos científicos relacionados à temática, tais como: reflexão, refração, energia luminosa, luz e sombra e outros. Como, na época, as crianças ainda não dominavam a escrita e a leitura, os dados sobre a experiência de visitação foram reunidos por meio de desenhos e comentários feitos por elas após terem percorrido todo o circuito da exposição. $O$ encantamento e a alegria durante a visita à exposição deixaram a certeza de que é possível tornar o conhecimento científico acessível para crianças dessa faixa etária e que

\footnotetext{
${ }^{+}$In the light of Science in Early Childhood Education: Challenging children's imagination to unravel optical phenomena

* Recebido: março de 2019. Aceito: julho de 2020.

1 E-mails: gfmarranghello@gmail.com; mmlucchese@gmail.com; angelahart2010@gmail.com
} 
a curiosidade é o elemento mais importante a ser explorado durante uma exposição interativa, pois elas se mantêm atentas e receptivas ao que lhes desafia a imaginação.

Palavras-chave: Luz; Educação Infantil; Exposição de Ciência.

\begin{abstract}
This work presents an analysis of the visitation of children from 4 to 6 years old to the exhibition "To the Light of Science in Early Childhood Education", promoted by the Universidade Federal do Pampa, based on a proposal for the dissemination and popularization of science on the theme of Light. The proposal was part of the celebration of the International Year of Light (2015), having received support from the Conselho Nacional de Desenvolvimento Cientifico e Tecnológico (CNPq) for its realization on two campuses: Bagé (in 2016) and Caçapava do Sul (in 2017). We describe in this work the thirteen stations of the exhibition circuit, analyzing how the children, accompanied by their teachers and university monitors, interacted with the experiments and artifacts, as well as their ability to express scientific concepts related to the theme, such as: reflection, refraction, light energy, light and shadow and others. As, at the time, the children still did not master writing and reading, the data on the visitation experience were gathered through drawings and comments made by them after having covered the entire exhibition circuit. The enchantment and joy during the visit to the exhibition left the certainty that it is possible to make scientific knowledge accessible to children of this age group and that curiosity is the most important element to be explored during an interactive exhibition, as they remain attentive and receptive to what challenges their imagination.
\end{abstract}

Keywords: Light; Child Education; Continuing Education; Non-formal Education; Science Exhibition.

\title{
I. Introdução
}

A educação científica leva em conta que ciência é cultura. Crianças e jovens são bastante curiosos e responder a essa curiosidade, começando desde cedo seu contato com as ciências, pode contribuir para que elas construam uma concepção positiva a respeito do conhecimento científico. Como o conhecimento científico é parte da cultura elaborada e 
acumulada pela humanidade, também as crianças têm o direito de se apropriar dela. Constituise, portanto, um ganho aprender ciência desde os primeiros anos de escolaridade, pois isso propicia uma melhor aprendizagem desse conhecimento no futuro e a aquisição precoce de uma cultura científica (HARTMANN, 2014).

A visitação de crianças a exposições de ciência e tecnologia tem sido descrita e analisada em diversos trabalhos (MIRANDA et al., 2010; STUDART, 2005; ISZLAJI, 2012, MASSARANI E NEVES, 2016). Esses trabalhos reforçam a defesa de Martins (2002, p. 18) do direito da criança de aprender ciência. Segundo a autora, invocar "uma suposta incapacidade intelectual das crianças é uma forma de discriminação social".

Sabemos que as crianças aprendem, desde muito pequenas, através da interação com o meio físico e social, observando, experimentando, imitando e recebendo instruções de pessoas mais experientes. De acordo com Rego (2009), elas também aprendem a fazer perguntas e a obter respostas para as questões que formulam. A preocupação, na Educação Infantil, todavia, volta-se, geralmente, para o ensino da linguagem oral, escrita e matemática, "mesmo sabendo que o Ensino de Ciências estimula avanços que podem concorrer para a qualidade de vida da humanidade, constituindo conhecimento vital para o desenvolvimento" infantil (ZUQUIERI, 2007, p. 137).

George Miley descreve o trabalho desenvolvido pelo Programa de Alto Alcance da pré-escola Perry, no qual crianças em situação de vulnerabilidade social participaram de um programa de formação para a ciência ${ }^{2}$. Este trabalho acompanhou as crianças, e um grupo controle, ao longo de suas vidas, desde a pré-escola até os 40 anos de idade, comparando dados relativos ao seu nível educacional e taxa de criminalidade, dentre outros. Fazendo uma avaliação consistente, foi possível verificar a importância de trabalhar ciências desde a Educação Infantil, obtendo resultados mais eficientes, quanto mais cedo se inicia este trabalho. $\mathrm{O}$ autor ainda se apoia na ideia de que as crianças pensam como cientistas, testando hipóteses, contrastando dados e fazendo inferências.

Visitar exposições de ciência e tecnologia é, portanto, uma excelente oportunidade para que elas aprendam conceitos científicos e explicações sobre fenômenos naturais. Miranda et al. (2010), fundamentando-se no referencial vygotskyano, analisaram desenhos feitos por crianças da Educação Infantil na faixa etária entre 4 e 5 anos, para compreender como acontece a formação de conceitos e de atitudes. De acordo com as autoras, para formar conceitos, a criança necessita perguntar, agir, ler o mundo, observar imagens, criar relações, testar hipóteses e refletir sobre o que faz, de modo a reestruturar constantemente o seu pensamento (MIRANDA et al., 2010, p. 181).

Ao pesquisar exposições interativas planejadas para o público infantil, Studart (2005), reforça a necessidade de ampliação da pesquisa na área, que carece de uma melhor compreensão de como esse público se relaciona com os materiais presentes nelas. O autor destaca que as crianças percebem as exposições como lugares estimulantes e onde as pessoas

\footnotetext{
${ }^{2}$ Disponível em: <http://www.unawe.org/about/audience/>. Acesso em: 04 jun. 2018.
} 
podem aprender. Além disso, durante as visitações, elas "Tiveram sentimentos positivos nesses espaços e relataram experiências prazerosas" (STUDART, 2005, p. 63).

Para registrar experiências sobre visitas a exposições, de crianças que ainda não leem ou escrevem, algumas pesquisas têm usado o desenho como forma divertida e agradável de fazê-las expressar suas memórias e percepções. Analisando desenhos feitos por crianças entre 5 e 8 anos sobre a exposição "Floresta dos sentidos", Massarani e Neves (2016, p. 71) buscaram acessar os interesses e memórias das crianças e constataram "que entre 15 e 25 dias após visita realizada a uma exposição interativa, as crianças foram capazes de expressar "memórias" sobre o espaço visitado, com grande riqueza de detalhes". A comemoração da UNESCO relativa ao Ano Internacional da Luz, em 2015, deu ensejo ao Conselho Nacional de Desenvolvimento Científico e Tecnológico ( $\mathrm{CNPq}$ ), em parceria com o Instituto TIM, fomentar atividades voltadas para a divulgação e popularização da ciência relacionadas à temática Luz. Os autores deste trabalho, docentes da Universidade Federal do Pampa (UNIPAMPA), aproveitando sua experiência em promover visitações de escolares a espaços não formais de educação, submeteram uma proposta para a criação da exposição, $\dot{A} L u z d a$ Ciência na Educação Infantil, voltada para crianças na faixa etária de 4 a 6 anos de idade ${ }^{3}$.

A exposição foi planejada para acontecer no município de Bagé, RS, e no município de Caçapava do Sul. Os dois municípios sediam campi da UNIPAMPA, instituição que funciona desde 2006, em dez municípios da região sul e sudoeste do Estado do Rio Grande do Sul. As duas exposições seguiram planejamentos semelhantes, com os organizadores fazendo, previamente, uma formação inicial com docentes da Educação Infantil e, depois, promovendo visitações de turmas de crianças entre 4 e 6 anos, de escolas públicas municipais, à exposição. As duas exposições, devido à disponibilidade, foram realizadas em espaços dos próprios campi da universidade. A primeira exposição, realizada no campus Bagé, foi antecedida por uma fase de planejamento e de construção dos materiais que vieram a compor ambas exposições. Essa etapa foi desenvolvida em 2015 e durante o primeiro semestre de 2016. Em Bagé a exposição aconteceu no segundo semestre de 2016 e em Caçapava do Sul no primeiro semestre de 2017.

Como a aquisição de uma cultura científica pressupõe uma alfabetização científica que, por sua vez, prevê "a aquisição de um vocabulário básico de conceitos científicos" (BRASIL, 2006 p. 18), a proposta pedagógica da exposição justifica-se pela teoria históricocultural de Vygotsky, que explicita a importância da aquisição da linguagem pelas crianças:

(...) a capacitação especificamente humana para a linguagem habilita as crianças a providenciarem instrumentos auxiliares na solução de tarefas dificeis, a superar a ação impulsiva, a planejar uma solução para um problema antes de sua execução e a controlar seu próprio comportamento. Signos e palavras constituem para as

\footnotetext{
${ }^{3}$ Algumas crianças que tinham 5 anos, quando iniciaram o último ano da Educação Infantil, já tinham completado 6 anos quando visitaram a exposição.
} 
crianças, primeiro e acima de tudo, um meio de contato social com outras pessoas (Vygostsky, 1991, p. 23).

A palavra constitui o signo usado para representar um conceito. À medida que o conceito é incorporado à estrutura cognitiva da criança, a palavra passa a ser para ela o símbolo daquele conceito. De acordo com Vygotsky (2008), os conceitos se formam e se desenvolvem na criança, sob condições internas e externas diferentes, dependendo da origem do aprendizado. Quando a criança aprende um conceito por meio da sua experiência pessoal, ele é um conceito espontâneo (ou cotidiano). Quando a origem do aprendizado é a escola, o conceito lhe é ensinado de forma sistemática e, muitas vezes, ela não o pode ver ou vivenciar diretamente. Trata-se, assim, de um conceito científico, pois sua origem é o conhecimento historicamente acumulado pela humanidade através da Ciência.

À medida que a criança se apropria dos conceitos científicos, ela vai tendo maior consciência dos processos mentais que emprega para dominá-los, ou seja, defini-los e operar com eles. Os conceitos científicos, devido ao seu sistema hierárquico de inter-relações, podem, mais tarde, ser transferidos a outros conceitos e a outras áreas do pensamento. Como afirma Oliveira (1992, p. 3): “O processo de ensino-aprendizagem que ocorre na escola propicia o acesso dos membros imaturos da cultura letrada ao conhecimento construído e acumulado pela ciência e a procedimentos metacognitivos, centrais ao próprio modo de articulação dos conceitos científicos".

Destacamos aqui o trabalho de Iszlaji (2012) que, fundamentada na teoria de Vygotsky, realiza uma análise do papel da criança de pouca idade dentro de museus de ciência e exposições voltadas para o público infantil. Em especial, a autora avalia o Museu de Ciência e Tecnologia da PUCRS, que possui uma área destinada a crianças de 3 a 6 anos.

Sabemos que conceitos como luz, sombra, cor, espelho e outros, usados para explicar os fenômenos apresentados na exposição, já são de conhecimento da criança, que os formou a partir da sua experiência pessoal, em contato com outras pessoas. Levando em conta esse pressuposto, durante a exposição, as crianças tiveram oportunidade de formular perguntas sobre os fenômenos mostrados. As explicações dos expositores e as respostas às suas perguntas tiveram por objetivo fazer com que elas se apropriassem de atributos científicos desses conceitos, de modo a permitir-lhes ampliar sua generalização.

Ao explicar como as crianças formam os conceitos científicos, Vygotsky (2008) afirma que, ao aprender uma palavra nova, a criança começa a formulação do conceito que essa palavra designa. À medida que seu intelecto se desenvolve, essa formulação é substituída por generalizações cada vez mais elevadas, até a formação do conceito em sua maior abrangência. A compreensão do significado das palavras, ou dos conceitos que elas designam, pressupõe "o desenvolvimento de muitas funções intelectuais: atenção deliberada, memória lógica, abstração, capacidade para comparar e diferenciar" Vygotsky (2008, p. 104). Por essa razão, começar relativamente cedo, o contato das crianças com palavras que designam 
atributos dos conceitos científicos, além de contribuir para o desenvolvimento das suas funções psicológicas superiores, revela-se promissor para formação da sua cultura científica.

A partir da elaboração do curso de formação e posterior exposição organizou-se o artigo da seguinte forma: (i) apresentação do planejamento da exposição; (ii) descrição das treze estações da exposição; (iii) discussão das compreensões das crianças sobre os experimentos e identificação dos fenômenos que conheceram ao visitarem a exposição. Por fim, apresenta-se uma discussão sobre os resultados da ação empreendida. Apesar da exposição ter sido realizada em dois municípios, a dinâmica, devido a particularidades locais, foi diversa e, por esse motivo, em alguns trechos do artigo é feita a referência de forma diferente para a exposição em Bagé e em Caçapava do Sul.

\section{A exposição: do planejamento à ação}

A exposição sobre a temática luz foi planejada, pelos autores deste artigo, de forma a contemplar um trabalho voltado ao Ensino de Ciências. Com base nos referenciais apresentados e na experiência dos autores em atividades de educação não formal para crianças das mais diversas faixas etárias, foram escolhidas as atividades que compuseram o circuito da exposição. Essas atividades foram apresentadas, inicialmente, à Secretaria de Educação do Município de Bagé, a qual convidou professoras da pré-escola para uma reunião de avaliação da proposta de exposição.

É sempre importante lembrar da carência que os cursos de pedagogia apresentam com relação à formação em Ciências (OVIGLI; BERTUCCI, 2009), ressaltando a importância do trabalho em espaços de educação não-formal, não apenas na promoção de exposições como também na formação continuada de professores.

Nessa reunião, que contou com a presença de 20 professoras, foi apresentada a proposta das estações, que iriam compor o roteiro da exposição. Durante o encontro, as professoras avaliaram a adequação e a pertinência das estações, principalmente com relação à interação das crianças com os experimentos. Foi anunciada, ainda, a intenção de realizar oficinas de formação continuada para as professoras, ao longo do ano, de modo que elas adquirissem proficiência em relação à linguagem científica a ser utilizada na exposição e pudessem contribuir para que as crianças também se apropriassem dela.

As oficinas, a primeira sobre o fenômeno da reflexão e a segunda sobre o fenômeno da refração, consistiram em uma aula teórica sobre conteúdos pertinentes à exposição e a construção de dispositivos ópticos. A oficina sobre refração propiciou a construção de periscópios e caleidoscópios, que foram levados para as escolas (Fig. 1). As crianças puderam decorar os aparatos antes de eles integrarem a exposição. Em outra oficina, as professoras realizaram experimentos que envolviam conceitos de densidade e miscibilidade, além de trabalhar com a lupa. Estas atividades também foram desenvolvidas com os alunos, antes da exposição. 


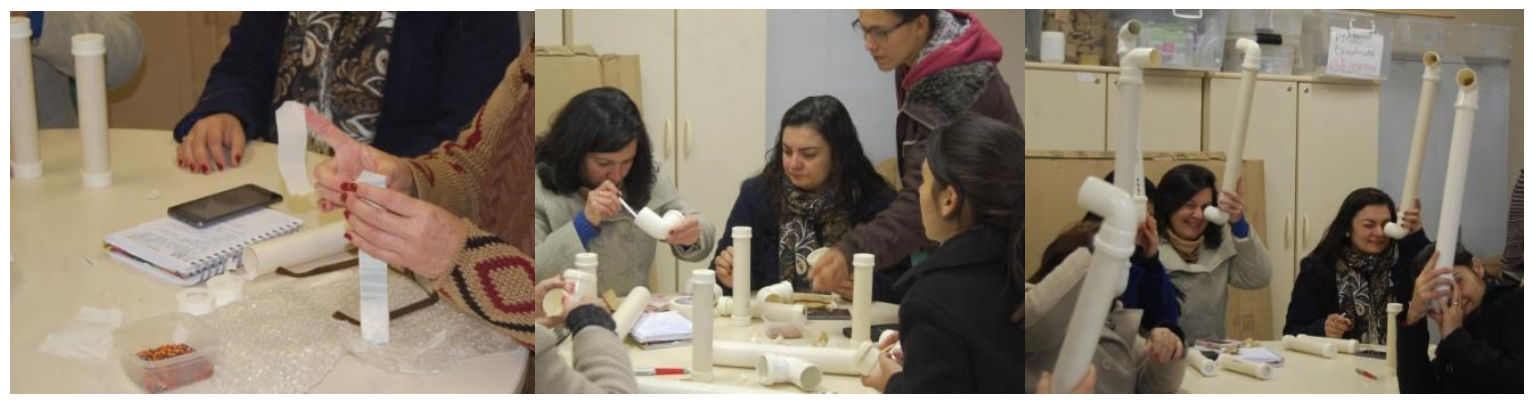

Fig. 1 - Professoras construindo caleidoscópios e periscópios sob orientação de monitores. Fonte: Acervo dos autores.

Depois de participar das duas oficinas, as professoras visitaram a exposição e percorreram as treze estações, recebendo orientações de como explicar cada uma delas para as crianças (Fig. 2). Além disso, elas puderam familiarizar-se com atividades que não tiveram contato durante as duas oficinas realizadas previamente.

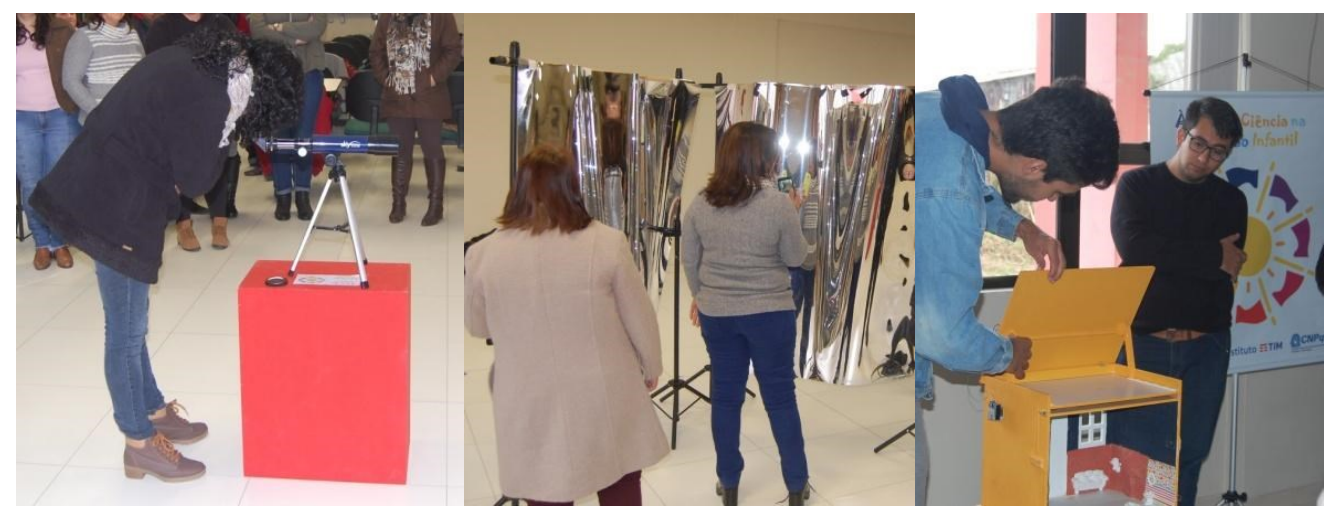

Fig. 2 - Professoras participando da oficina de preparação para visita à exposição. Fonte: Acervo dos autores.

A proposta inicial era que cada professora, ao trazer seus alunos para visitar a exposição explicasse o que eles veriam nela. A prática, no entanto, se mostrou diferente do esperado. As professoras não se sentiram seguras para explicar os experimentos e os monitores conduziram a dinâmica de visitação.

\section{II.1 As Visitas à Exposição}

A exposição foi organizada, nos dois campi, de modo a ter apenas uma turma de crianças percorrendo a exposição de cada vez. A cada dia podiam ser atendidas uma turma no turno da manhã e outra no turno da tarde. A duração da visita variava de uma hora e meia a duas horas, de acordo com o número de crianças visitantes. Em Bagé, a exposição ficou aberta para visitação durante duas semanas. Em Caçapava do Sul, 206 crianças, de quatorze (14) escolas municipais, visitaram a exposição durante as três semanas em que ela esteve 
aberta no campus. A cada visita, eram recebidas de 7 a 17 crianças com suas respectivas professoras.

A turma de crianças chegava aos campi com o transporte escolar do município. As crianças, a professora e algum eventual auxiliar, que os acompanhavam, eram recepcionados pelos organizadores da exposição (autores deste trabalho) e pelos monitores, alunos dos cursos de graduação de cada campus. No campus Bagé, a exposição aconteceu numa sala de aula, especialmente preparada para o evento, com pouco mais de $80 \mathrm{~m}^{2}$. No campus Caçapava do Sul, a exposição aconteceu no auditório, um espaço de $211 \mathrm{~m}^{2}$, mas ocupando apenas parte dele, uma vez que o local também é utilizado para outras atividades realizadas no campus.

Ao chegar, professoras e auxiliares vestiam um jaleco branco com o logotipo da exposição, igual ao utilizado pelos monitores. O jaleco pretendia criar o ambiente do imaginário infantil sobre a ciência e identificar a professora como a monitora da exposição. As 13 estações da exposição foram dispostas, em cada campus, de acordo com o espaço disponibilizado. As crianças percorriam as estações acompanhadas pela professora e pelos monitores, conforme roteiro organizado previamente.

A sequência da exposição procurou utilizar estações interativas, remetendo aos conceitos de reflexão e refração, bem como os instrumentos ópticos e suas finalidades. Cabe ressaltar que a maioria dos elementos presentes nas estações da exposição foi construída pelos professores que elaboraram a exposição, com recursos do projeto e a descrição de cada elemento encontra-se detalhada em Hartmann, Lucchese e Marranghello (2017). Descreve-se a seguir o roteiro seguido pelas crianças e professoras ao longo da exposição.

\section{II.2 Estação 1: Boas Vindas}

A recepção das crianças era feita por um "holograma", no qual um astronauta as convidava a entrar e conhecer a exposição. O "holograma" foi elaborado pelos organizadores da exposição e consistia de uma TV 42", uma estrutura metálica e três placas de vidro montadas no formato de uma pirâmide. Este efeito "holográfico" origina-se a partir imagem gerada pela televisão cujos raios luminosos são refletidos pelas placas de vidro e formavam uma imagem virtual projetada no centro do dispositivo. A técnica é bem conhecida e foi muito usada pelos meios artísticos como o "fantasma de Pepper". No Brasil, era conhecida como "Casa da Monga" (MEDEIROS, 2008). Dentro da pirâmide, foram colocados alguns objetos feitos em madeira, especialmente para a exposição (foguete, planeta e dois personagens), de forma a aumentar a sensação de profundidade.

Durante a apresentação, um astronauta aparecia flutuando e anunciava a exposição e o que estava por iniciar. As crianças assistiam fascinadas, algumas se aproximavam para tentar compreender o que estava acontecendo, enquanto outras assistiam sentadas em um tapete colocado em frente à pirâmide holográfica (Fig. 3a). Ao término da introdução, as crianças eram convidadas a observar mais de perto e instigadas a expor suas ideias sobre o funcionamento de tal aparato. 


\section{II.3 Estação 2: Aquário}

Logo ao lado da pirâmide holográfica, as crianças encontravam uma imagem impressa em um painel fixado na parede, representando o fundo do mar, contendo peixes de diversos tamanhos. As crianças recebiam lupas para procurar os peixes nesta imagem, que denominamos de aquário. Dependendo da turma, as crianças eram divididas em trios ou quartetos para que uma não obstruísse a visão de outra. $\mathrm{O}$ fenômeno que podia ser observado pelas crianças era a ampliação dos objetos com o uso de lentes convergentes.

Algumas crianças inspecionavam o aquário por completo, com muito empenho em desvelar o paradeiro de pequenos peixinhos escondidos atrás de corais, enquanto outras passavam rapidamente pela estação (Fig. 3b). Novamente, as crianças eram perguntadas sobre a função da lupa naquela brincadeira de procurar os peixinhos.

\section{II.4 Estação 3: Casa Mágica}

Uma caixa escura foi construída para que as crianças observassem através de uma pequena abertura a "troca de roupa" de duas bonecas. No interior da caixa duas bonecas foram dispostas de forma que a reflexão da imagem de cada uma delas formasse uma imagem virtual na pequena abertura. A imagem aparecia no momento que as crianças acionavam a luz sobre as bonecas. Os monitores indicavam para as crianças que as luzes fossem ligadas uma de cada vez. Neste experimento, o princípio físico de geração da imagem é o mesmo da "Casa da Monga".

$\mathrm{Na}$ Casa Mágica, após todas as crianças realizarem suas observações, os monitores as questionavam para que tentassem explicar o que estava acontecendo no interior da caixa, Fig. 3c. Só depois das formulações das hipóteses é que a tampa superior era retirada e elas podiam observar seu funcionamento. Elas eram, então, incentivadas a reelaborar sua explicação sobre o que haviam observado. Chamou a atenção, neste momento que uma criança cuja concentração era constantemente requisitada pela professora. Ao ser questionada sobre o funcionamento da caixa mágica, a criança respondeu, apontando com o dedo, que ora a luz percorria um trajeto e ora percorria outro, dependendo qual das lâmpadas era acesa.

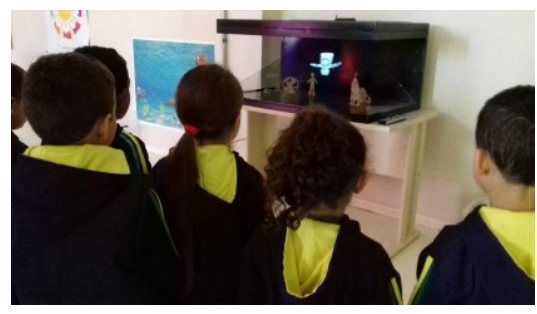

(a)

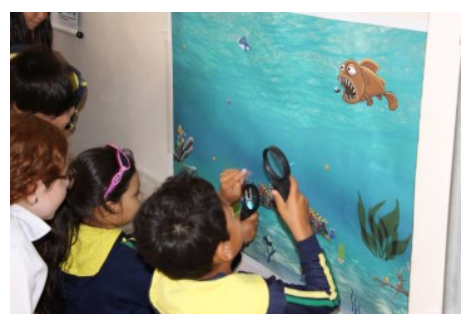

(b)

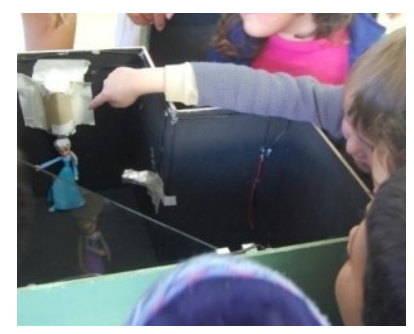

(c)

Fig. 3 - Estações da Exposição, (a) boas vindas, (b) aquário e (c) caixa mágica. Fonte: Acervo dos Autores. 


\section{II.5 Estação 4: Casa Solar}

Neste experimento, as crianças observavam, no protótipo de uma pequena casa, como se pode acender as luzes e ligar ventiladores sem que esses dispositivos elétricos estivessem ligados a uma rede de energia. O princípio de funcionamento é que esta pequena casa possui circuitos com LED e um motor acionado por uma placa fotovoltaica, pequenos interruptores para acionar e desligar estes itens, além de elementos lúdicos como móveis e personagens. O conceito aqui trabalhado é o de que a luz solar pode ser usada para geração de energia de forma renovável (LUCCHESE; MACHADO, 2017).

A Casa Solar, em Bagé, foi exposta no lado de fora da sala (sempre que o tempo permitia). Em dias nublados ou chuvosos, utilizava-se uma lâmpada para iluminar e ativar a placa fotovoltaica. Em Caçapava do Sul, a Casa Solar recebia uma boa insolação e não foi necessário levá-la para um local externo. Durante a visita a essa estação, as crianças eram desafiadas a responder: "o que acontece quando se altera a inclinação do telhado da casa, consequentemente da placa solar?".

\section{II.6 Estação 5: Bancada da Experiência}

Uma bancada na altura das crianças foi montada para realização do experimento em que substâncias com cores e densidades diferentes eram colocadas em um único recipiente, formando um arco-íris de líquidos. As substâncias não se misturavam e se arranjavam dentro do recipiente de acordo com a sua densidade. Na Bancada da Experiência, antes de misturar as substâncias, as crianças podiam colorir com corante alimentício alguns dos líquidos e, por vezes, colocá-los no recipiente (Fig. 4a). Seguidamente, uma criança levantava um questionamento que era testado, como, por exemplo, a inversão da ordem de colocação das substâncias dentro do recipiente.

Os principais conceitos relativos a este experimento não estão relacionados diretamente à óptica ou à luz, mas a bancada foi inserida no programa da exposição para ilustrar a construção de um arco-íris dentro de um tubo de ensaio, permitindo o trabalho com a mistura (ou não) de cores. Como este era um momento em que as crianças tinham mais liberdade de testar hipóteses, como a inversão da ordem dos líquidos ou o uso de diferentes corantes, os autores consideraram esta estação importante para o trabalho com ensino de ciências.

\section{II.7 Estação 6: Teatro de Sombras}

O Teatro de Sombras foi montado com um pano branco preso em uma estrutura metálica e iluminado com uma fonte de luz branca. Bonecos de madeira foram elaborados de forma a representar os personagens de uma das sessões do Planetário da Unipampa. A sessão foi adaptada na forma de diálogo para que pudesse ser apresentada como uma peça de teatro. O objetivo desta estação era que as crianças pudessem de forma lúdica interagir com a sombra 
e observar sua formação. Nesta estação, as crianças podiam observar que um objeto, como o foguete de madeira, era capaz de bloquear a passagem da luz, formando as sombras, enquanto outros, como o pano branco do teatro, permitia a passagem da luz.

Inicialmente, as crianças assistiam passivamente ao teatro, protagonizado pelos monitores da exposição. Após a encenação, as crianças eram convidadas a passar para o outro lado do palco e construírem suas próprias peças teatrais, manipulando os personagens de madeira. Neste momento, as crianças ainda podiam observar a tridimensionalidade, a sobreposição e a mudança no tamanho das sombras quando os objetos são aproximados ou distanciados da fonte de luz.

\section{II.8 Estação 7: Mistura de Cores}

Três refletores de LED, nas cores azul, amarelo e vermelho iluminavam uma parede branca, contendo algumas áreas de intersecção que resultava na mistura de cores. As crianças podiam passar diante das luminárias para ver as sombras coloridas que se formavam na parede. A luz pode ser composta (ou decomposta) em diversas cores e suas combinações geram novas cores. Nesta estação, as crianças podiam ver a mistura de cores e sua composição e, também interagir passando suas mãos na frente das luminárias ou, seguidas vezes, desfilar diante delas para ver como suas sombras (projetadas na parede) iam se modificando ao longo do trajeto percorrido (Fig. 4b).

É importante ressaltar que, ao inserir um objeto, mão ou corpo na frente de uma lâmpada, projetamos uma sombra colorida pelas demais lâmpadas, o que acaba sendo inesperado, uma vez que estamos acostumados com sombras escuras. Assim, reunimos, na exposição, conceitos como sombras e mistura de cores, pouco explorados nas estações anteriores.

\section{II.9 Transição}

O momento de maior liberdade para as crianças ocorria na transição entre a Estação da Mistura de Cores (Fig. 4b) e a Estação do Telescópio (Fig. 4c). Neste momento, elas apenas circulavam, com acompanhamento mínimo, utilizando os periscópios e caleidoscópios (já vistos na escola), passando também pelo Espelho Deformador.

\section{II.10 Estação 8: Caleidoscópio e Periscópio}

Os caleidoscópios e periscópios (Fig. 5a) construídos pelas professoras durante as oficinas foram decorados pelas crianças nas escolas e ficaram disponíveis para a exposição (Fig. 5b). Em ambos os equipamentos as crianças podiam observar como a luz pode refletir múltiplas vezes em espelhos e como podemos usar a reflexão para construir alguns aparatos.

As janelas da sala de exposição eram mais altas que as crianças e os periscópios estavam organizados de forma a permitir que elas observassem o lado de fora da sala. Desta 
forma, as crianças se dividiam entre se encantar com a possibilidade de ver a rua ou de encontrar um objeto que ela tinha ajudado a construir.

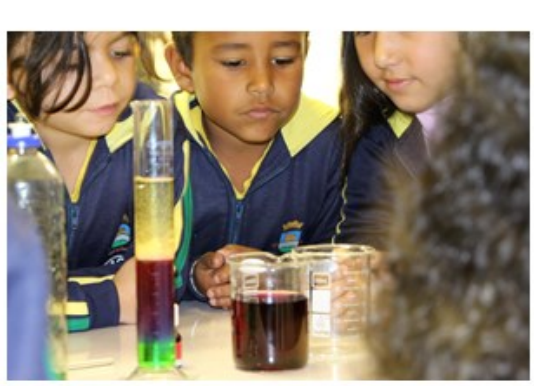

(a)

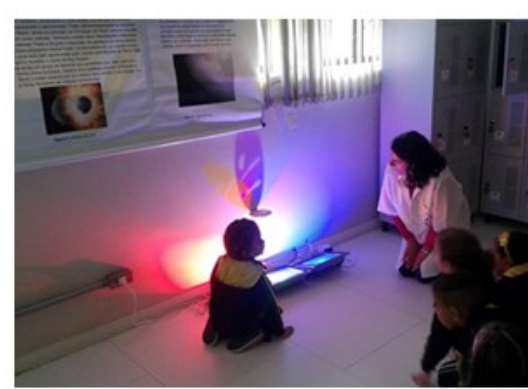

(b)

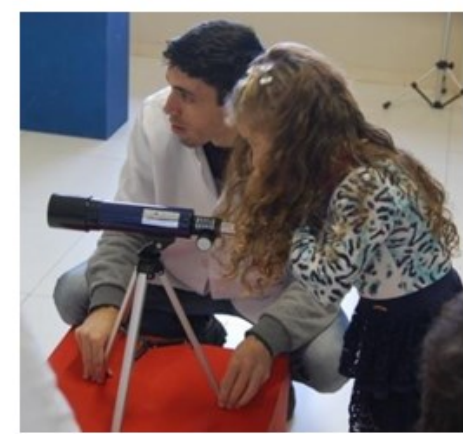

(c)

Fig. 4 - Crianças em visita à exposição, (a) Bancada da experiência, (b) Mistura de cores e (c) Telescópio. Fonte: Acervo dos Autores.

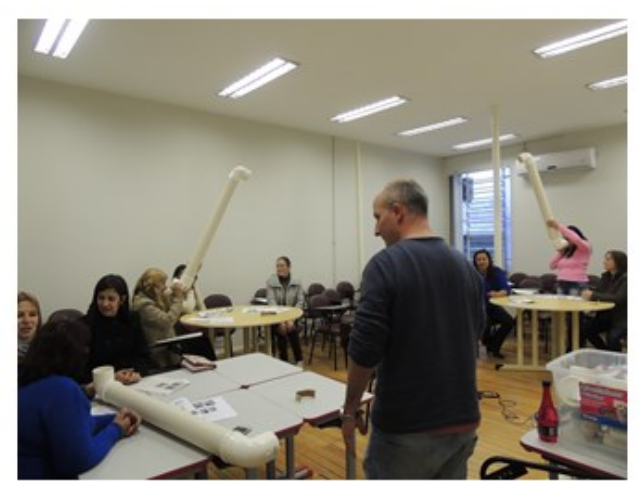

(a)

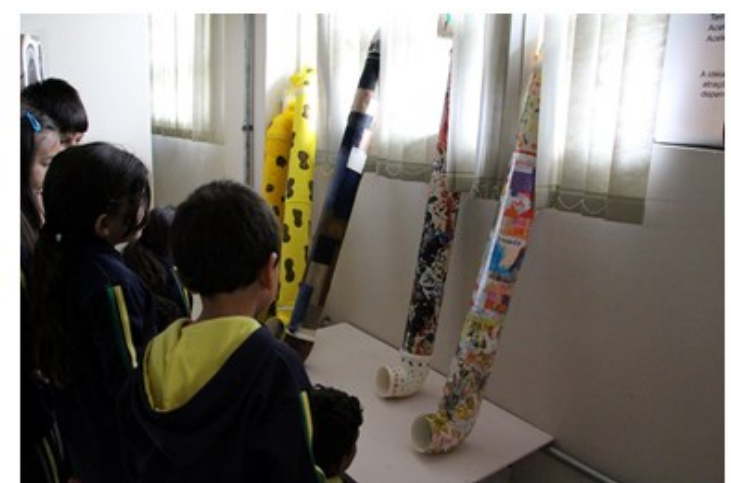

(b)

Fig. 5 - Oficina de Periscópios (a) e visita das crianças na exposição (b). Fonte: Acervo dos Autores.

\section{II.11 Estação 9: Espelho Deformador}

Duas folhas refletoras foram presas em suportes metálicos formando dois espelhos irregulares de forma a alterar a imagem como tradicionalmente enxergamos em espelhos planos. Nesta estação, as crianças podiam confrontar sua perspectiva tradicional do uso do espelho plano com um processo de reflexão que deforma a imagem. Em frente aos espelhos, as crianças se divertiam, colocando-se em diversas posições para observar como sua imagem era refletida. Ao se verem refletidos mais gordinhos, mais baixos, mais compridos, divertiamse com a formação de suas imagens.

\section{II.12 Estação 10: Telescópios}

Um pequeno telescópio apontava para a segunda estação (aquário). Desta forma, o telescópio era apresentado como um aparato que nos permite ver coisas que estão muito 
distantes. Como o telescópio utilizado era do tipo refrator, os expositores aproveitavam para contar às crianças que ele era construído com lentes como aquela utilizada na lupa.

Nesta estação, as crianças se dividiam entre aquelas que pouco se detinham à observação e outras que retornavam ao final da fila para poder ter mais uma chance de experimentar o uso do telescópio.

\section{II.13 Estação 11: Microscópio}

Um microscópio, acoplado a uma câmera, mostrava a pata de um mosquito projetada na parede. Em oposição ao recém apresentado telescópio, nesta estação as crianças encontravam o microscópio como sendo um aparato que nos permite ver coisas muito pequenas.

A opção de usar um microscópio com a imagem projetada na parede foi para dar mais flexibilidade e autonomia para as crianças visualizarem a pata do mosquito, mas a observação direta, através do microscópio, também foi oferecida e, assim como o uso do telescópio, provocou encantamento nas crianças.

\section{II.14 Estação 12: Sala Escura}

Para visitar esta estação, cada criança recebia uma lanterna e, saindo da sala da exposição, seguiam pegadas coloridas no chão até uma sala montada de forma a ser um ambiente totalmente escuro. Ao entrarem nesse espaço, com as lanternas acesas, encontravam a sala iluminada com luz branca e negra. Ao apagarem as lanternas, as luzes do ambiente eram apagadas, revelando os segredos da sala decorada com elementos fluorescentes, como pinturas reproduzindo estrelas, letras e números. Nesse momento, as crianças ficavam maravilhadas, pois podiam observar que alguns elementos brilham no escuro. Antes de retornar para a exposição, era acesa apenas a luz negra, ressaltando os itens fluorescentes (Fig. 6a). A opção pelo uso das lanternas no trajeto e entrada da sala escura foi para dar segurança às crianças que, nesta faixa etária, ainda apresentam medo do escuro. Na Fig. $6 \mathrm{~b}$ as crianças seguem os passos para retornar a sala de exposição.

É impossível apontar uma única visita em que este não tenha sido o momento de maior encantamento das crianças. Do mistério de um passeio com lanternas na mão até a entrada em uma (quase) caverna recheada por elementos fluorescentes, esta estação foi inserida como último espaço a ser visitado para facilitar a mobilidade das crianças e devido à nossa expectativa, plenamente confirmada, de que pudesse se tornar o clímax da exposição.

No campus Bagé, essa sala foi montada embaixo de uma das escadarias do prédio. No campus Caçapava do Sul, esse ambiente foi construído sobre o palco do auditório usando um anteparo e cortinas pretas presas no teto. 


\section{II.15 Estação 13: Desenho}

Ao retornar para o espaço da exposição, as crianças eram convidadas a fazer desenhos, daquilo que mais haviam gostado na visita. $\mathrm{O}$ desenho era feito com canetas de diversas cores sobre uma transparência fixada em uma prancheta. Cada criança, que concluía o seu desenho, era convidada a explicá-lo para todos. Usando um retroprojetor (equipamento elétrico utilizado para a projeção e ampliação de imagens), a transparência era projetada em uma parede (Fig. 6c).

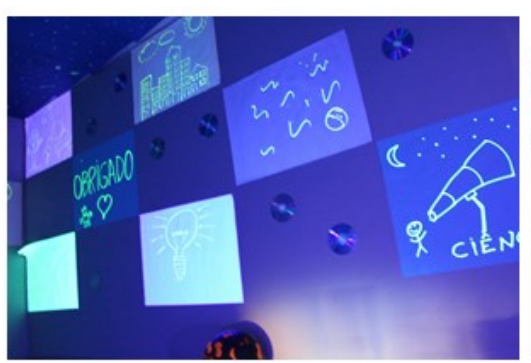

(a)

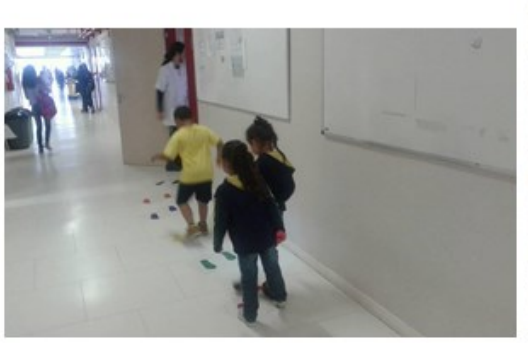

(b)

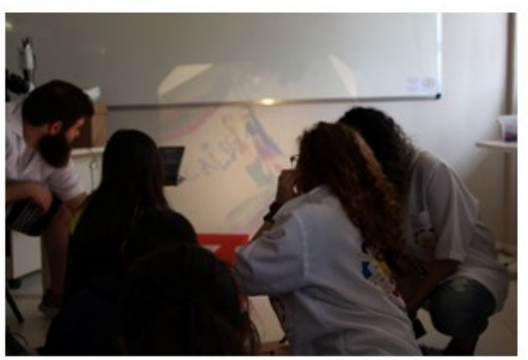

(c)

Fig. 6 - (a) Sala Escura, (b) Retorno da sala escura e (c) Apresentação dos desenhos. Fonte: Acervo dos Autores.

As crianças podiam levar seus desenhos para casa ou para a escola, como forma de guardar uma lembrança da exposição e instigar os pais a perguntar sobre a atividade de que haviam participado. Aquelas que não queriam levar os desenhos podiam deixar como uma lembrança sua aos monitores da exposição.

\section{Avaliando os resultados das oficinas e visitações}

Ao longo da exposição procurou-se avaliar como as crianças entendiam o que viram e experienciaram durante a visitação. Para isto, foram observadas as atitudes das crianças durante a realização das atividades, anotados seus comentários, realizada uma entrevista coletiva com as professoras de Bagé, solicitado que as professoras dos dois municípios respondessem um questionário avaliativo da exposição, e analisados os desenhos das crianças.

Sobre o material desenvolvido nas oficinas (periscópio e caleidoscópio), as professoras destacaram a importância deles estarem na exposição. As crianças haviam decorado o periscópio como se fosse uma girafa e, segundo a professora, ao encontrá-lo na exposição, mencionaram “Olha lá a girafa!”. Uma professora destacou vários aspectos como: "Eles ficaram dias me perguntando [...] Tivemos que ir para a quadra ver a sombra."

No questionário, as professoras que preencheram o espaço destinado a comentários registraram que as crianças comentaram sobre a visita à exposição durante vários dias. 
Em geral, todas as crianças ficaram encantadas, porque era algo novo, que de alguma forma eles participaram na construção como o periscópio. Sempre que visualizam os desenhos finais, que estão expostos na sala, comentam que é o desenho dos planetas.

Os alunos amaram a nova experiência e passaram a semana inteira comentando sobre a mesma. Eles ficaram encantados.

Por fim, citando exemplos específicos das atividades da exposição e como as crianças passaram a demandar novas experiências na sua escola.

As crianças adoraram o jogo de luzes, casinha solar e a sala escura até quiseram que a sala também tivesse o canto escuro.

Algumas professoras relataram que era a primeira vez que as crianças faziam um passeio fora da escola ou era a primeira vez que saíam do seu bairro para um passeio.

Alguns comentários finais, reunidos durante a reunião com as professoras de Bagé trouxeram a dimensão destas atividades realizadas na "casa bem grande", forma como um aluno descreveu a universidade. As professoras mencionavam ter visto um "brilho no olhar" das crianças ao referir-se à visita à exposição e destacaram que a atividade "além da criança envolveu a família", pois elas "relataram detalhes" que deixaram os "pais curiosos se fizeram tudo aquilo".

No campus Caçapava do Sul, não foi realizada uma entrevista com as professoras após a visita à exposição. A avaliação do evento expositivo restringiu-se a solicitar às 20 professoras, que participaram da formação continuada e depois levaram seus alunos para visitar a exposição, a responder o questionário. Como o questionário foi entregue no período em que as professoras ainda estavam em férias, conseguiu-se que apenas cinco delas o retornassem respondido.

Quatro professoras assinalaram apenas a primeira coluna do questionário, considerando adequada a exposição à faixa etária de 5 a 6 anos. Duas dessas professoras registraram que teriam dúvidas se gostariam de desenvolver atividade similar sobre outro tema de ciências no ano seguinte. A quinta professora, apesar da avaliação positiva em 9 dos 12 itens do questionário, destacou em suas respostas que teria dúvidas se conseguiria construir o material produzido nas oficinas e considerou a exposição pouco adequada à faixa etária de 5 a 6 anos, justificando sua resposta:

As crianças gostaram, pois era tudo muito encantador, despertou curiosidade, porém não compreenderam como aconteciam as experiências, o porquê de tal "fenômeno"...

De acordo com Moreira (2011), um instrumento é algo usado para fazer alguma coisa. As sociedades criam instrumentos e sistemas de signos e a combinação de ambos permite o desenvolvimento de funções mentais ou processos psicológicos superiores. Tendo em vista esse pressuposto, a exposição foi organizada de modo a oferecer às crianças oportunidades de contato com objetos que lhes permitissem "fazer algo" enquanto visitavam 
as estações. Entre os instrumentos (objetos), possíveis de serem manipulados pelas crianças para compreender os fenômenos ópticos ilustrados na exposição havia a lupa, a luneta, o periscópio, os espelhos, os refletores de luz colorida e as marionetes do teatro de sombra.

Nesse sentido, o maior ganho da visita foi fazer com que as crianças aprendessem se divertindo a respeito dos fenômenos ópticos ilustrados em cada uma das estações. Pudemos observar que, para algumas, a reflexão da luz era um fenômeno fácil de entender. Ao serem desafiadas a explicar por que, na Casa Mágica, podiam ser vistas duas bonecas diferentes, quando era acionado o interruptor, algumas crianças simplesmente diziam: “A luz 'bate' aqui e ali e mostra uma boneca de cada vez". Elas podiam não usar a palavra adequada para o fenômeno, mas compreendiam como se dá o fenômeno da reflexão.

Fazendo referência a Tolstoi ${ }^{4}$, Vygotsky (2008) afirma que quando a criança ouve ou lê uma palavra desconhecida e essa palavra é repetida em outra frase, mais cedo ou mais tarde ela sentirá a necessidade de usá-la. Uma vez que a tenha usado, a palavra e o conceito lhe pertencem. Porém, "o ensino direto dos conceitos é impossível e infrutífero" (VYGOTSKY, 2008, p.104). Em outras palavras, um conceito não pode ser simplesmente transmitido pelo professor, pois leva a um verbalismo vazio, uma repetição de palavras pela criança que, à semelhança de um papagaio, simula um conhecimento que não possui. Assim, é necessário que ela, além de usar o signo (a palavra) que simboliza o conceito, o experimente através de um instrumento de mediação.

A dificuldade em trabalhar com crianças da Educação Infantil reside na forma de obter dados sobre suas impressões sobre a experiência de visitar a exposição. Suas ações e falas durante a exposição constituem a principal forma de reunir informações para avaliar o alcance do trabalho. O desenho apresentado pelas crianças ao final da exposição foi capaz de trazer informações sobre a qualidade do material e o interesse despertado nelas com relação a cada um dos itens expositivos. Cabe lembrar que: "O desenho é uma das principais formas de expressão infantil, sendo necessário escutar os relatos de seus registros para melhor compreender como pensam sobre determinados conceitos" (MIRANDA et al., 2010, p. 193).

De acordo com estudos de Vygotsky (2009) sobre o ato de desenhar da criança, esse é um tipo predominante de criação na primeira infância, que se estende até os 10 ou 11 anos. Ao chegar nessa idade, as crianças, de um modo geral, perdem o interesse por desenhar, que ressurge entre os 15 e 20 anos nos sujeitos que possuem um dom artístico elevado ou aqueles que receberam algum estímulo externo para continuar desenhando.

$\mathrm{O}$ desenhar é para a criança entre cinco e sete anos uma narrativa gráfica, pois enquanto desenha, ela pensa no objeto que está representando como estivesse falando dele. Até os cinco anos, conforme estudos do psicólogo Georg Kerschensteiner (1854-1932), a criança situa-se no estágio dos esquemas, desenhando de memória e não pela observação dos objetos. A criança desenha o que sabe e o que considera essencial sobre o objeto representado e não sobre o que vê ou o que imagina sobre ele. Ao desenhar, por exemplo, uma pessoa a

${ }^{4}$ Tolstoi, L. Pedagogichheskiestat'I (Ensaios Pedagógicos). Kushnerev, 1903. 
cavalo, desenha as duas pernas, apesar de ver apenas uma delas. Entre seis e sete anos, a criança produz desenhos do tipo raio-x. Ao desenhar uma figura humana, ela traça, sob as roupas, as pernas que não vê, produzindo uma representação formal mista, numa tentativa de tornar a imagem mais semelhante ao objeto. Trata-se de um esquema misturado com a aparência ou a forma de algo (VYGOTSKY, 2009).

Pode-se observar que os interesses das crianças na exposição foram variados e elas retrataram em seus desenhos objetos diferentes. Para algumas, chamava atenção o Teatro de Sombras, enquanto para outras a Sala Escura era o que mais as tinha fascinado. Algumas desenhavam apenas um item da exposição, enquanto outras desenhavam vários. Todos os itens da exposição chamaram a atenção de alguma criança e não é possível dizer qual deles foi o que mais as impactou. Como várias crianças levaram os desenhos consigo, não foi possível quantificar os registros feitos por elas em seus desenhos.

Ao solicitar que as crianças descrevessem seus desenhos e, também, durante seus questionamentos e falas durante a visita às estações, foi possível observar que elas aprenderam palavras novas, como reflexão, refração e densidade, e conheceram objetos que não faziam parte do seu cotidiano como a placa solar e o telescópio. Para saber quanto dessa exposição realmente foi apreendida pelas crianças, seria necessário acompanhar seu desenvolvimento escolar, o que está muito além das possibilidades desta pesquisa. O que se sabe é o que foi relatado pelas professoras nos questionários e na entrevista.

Apresentamos, a seguir, algumas imagens que retratam, de forma geral, os desenhos produzidos pelas crianças. É importante salientar que todos estes desenhos foram explicados enquanto elas os exibiam com auxílio do retroprojetor. Algumas das imagens aparecem recortadas ou com tarjas para encobrir os nomes das crianças que apareciam nos desenhos. Em alguns casos, como na Fig. 7, é quase impossível decifrar o desenho da criança sem sua explicação. O desenho da sala escura representa o que ela sabe sobre esse ambiente: que, logo ao entrar, não se veem os detalhes do seu interior. Como afirma Vygotsky (2009, p.108), o "pequeno pintor é bem mais um simbolista do que um naturalista; ele não se preocupa nem um pouco com a semelhança completa e exata e deseja apenas as indicações superficiais".

Entre os desenhos que ficaram com os organizadores, observamos que a Sala escura foi a estação mais representada pelas crianças. Por vezes, a sala era representada como um todo, conforme mostra a Fig. 7, outras vezes era desenhada com as crianças dentro dela, como na Fig. 8a. É importante salientar que havia uma imagem fosforescente dentro da sala escura que retratava uma escola, tal qual foi representada pela criança na Fig. 8b e que, durante seu relato, a criança se referiu a esta escola como sendo aquela vista na sala escura.

A Fig. 9a foi escolhida, pois é uma representação de que, para algumas crianças, o simples fato de realizar um passeio foi extremamente marcante e o desenho representa, em geral, fatos que decorreram na viagem da escola até a universidade, incluindo a paisagem, animais, veículos e outros. 


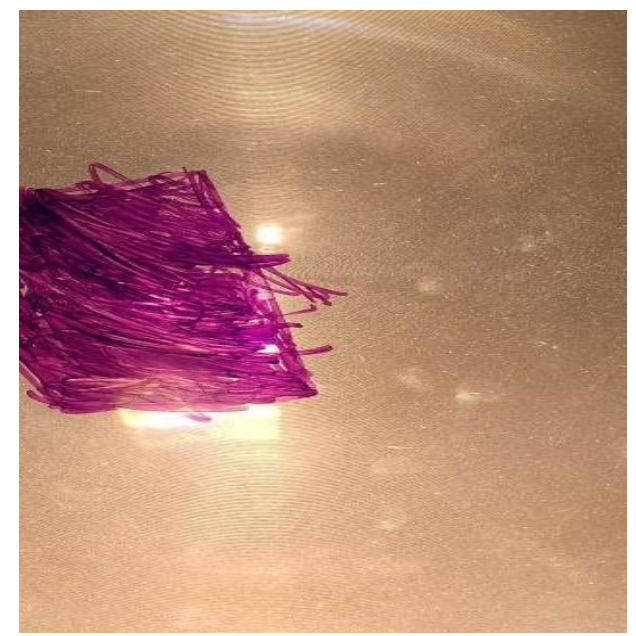

Fig. 7 - Desenho da criança representando a Sala Escura. Fonte: Acervo dos autores.

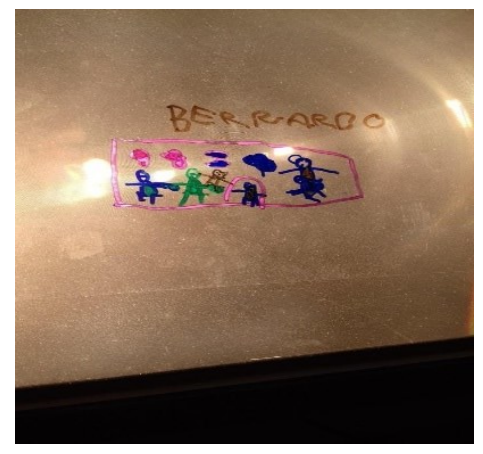

(a)

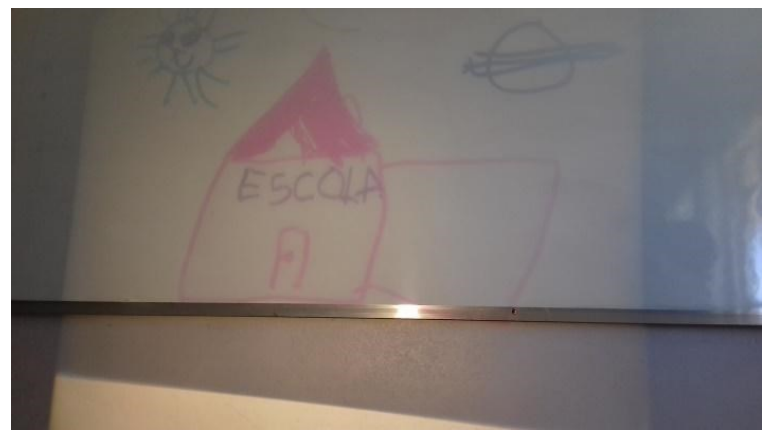

(b)

Fig. 8-Representações da Sala Escura. Fonte: Acervo dos autores.

Por fim, é importante ressaltar a presença de outra classe de desenhos. No campus Bagé, a exposição foi montada na sala onde, normalmente são feitas sessões com o planetário inflável. Durante o período da exposição, o planetário estava guardado em outro local, mas uma parte da decoração da sala permaneceu. O que permaneceu durante a exposição foi uma maquete que retratava o Sistema Solar. A maquete estava pendurada no teto da sala e foram muitos os desenhos que retrataram estes planetas, como, por exemplo, o da Fig. 9b.

Conforme destaca Vygotsky (2009), os desenhos de crianças na faixa de cinco a seis anos são bem racionais, pois contemplam somente os aspectos essenciais e constantes dos objetos. "Ao desenhar, a criança transmite no desenho o que sabe sobre o objeto, e não o que vê" (VYGOTSKY, 2009, p.108). No caso dos planetas, o essencial para essa criança é que os planetas são circulares e têm cores diferentes. 


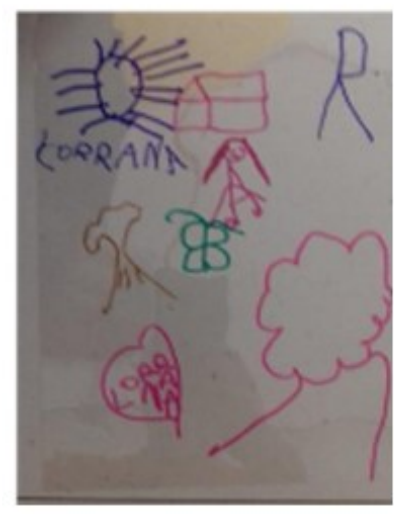

(a)

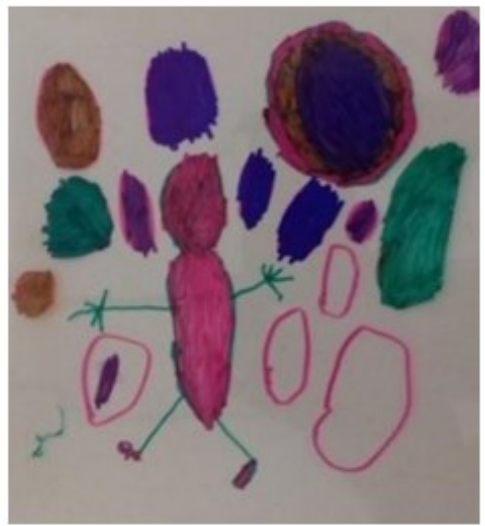

(b)

Fig. 9 - Representação do passeio (a) e dos planetas (b) presentes na sala. Fonte: Acervo dos autores.

\section{Considerações finais}

A experiência de promover a exposição constituiu um aprendizado para todos participantes, desde os organizadores e professoras da Educação Infantil até crianças e monitores. Para os organizadores, foi um desafio planejar e construir estações que pudessem ilustrar fenômenos ópticos e, ao mesmo tempo, serem atrativas para crianças de 4 a 6 anos. Para as professoras, foi um complemento de sua formação profissional e um incentivo para que trabalhem com Ciências com crianças que ainda não leem e escrevem, mas que são capazes de expressar o que compreendem em situações de aprendizagem. Para os monitores, alunos de cursos de graduação, foi um desafio tornar simples explicações sobre conceitos aprendidos por meio de definições formais. Vários deles afirmaram ter que parar para pensar "como explico isso para uma criança tão pequena?" Esse exercício de explicar o, aparentemente, complicado de forma simples fez a todos (professores e monitores) repensar o quanto a ciência pode ser atrativa e desafiante.

$\mathrm{O}$ encantamento e a alegria das crianças durante a visita à exposição compensaram amplamente todo o trabalho, deixando, aos responsáveis pela sua realização, a certeza de que é possível tornar o conhecimento científico acessível para qualquer pessoa, de acordo com o seu nível de compreensão. A curiosidade das crianças é o elemento mais importante a ser explorado durante uma exposição interativa, pois mantém as crianças atentas e receptivas ao que lhes desafia a imaginação. Elas queriam entender por que o espelho deforma a imagem?; por que a luz acende uma lâmpada quando a luz solar incide sobre uma célula fotovoltaica?; por que os instrumentos podem ampliar a imagem de objetos distantes ou próximos?; por que pinturas fluorescentes brilham no escuro?. São muitos os porquês e simples as respostas que podem contribuir para o aprendizado das Ciências. 


\section{Agradecimentos}

Os autores agradecem ao CNPq, processo 445712/2015-5, pelo financiamento da exposição.

\section{Referências}

HARTMANN, A. M. Educação e Cultura Científica: a participação de escolas como expositoras na Semana Nacional de Ciência e Tecnologia. Curitiba, Appris, 2014. 425 p.

HARTMANN, A. M.; MARRANGHELlO, G. F.; LUCCHESE, M. M. À luz da ciência na educação infantil, Itajaí, Casa Aberta, 2017. 56 p. Disponível em:

$<$ https://sites.unipampa.edu.br/planetario/files/2019/04/a-luz-da-ciencia.pdf $>$. Acesso em: 30 jun. 2020.

ISZLAJI, C. A. A criança nos Museus de Ciência: Análise da exposição mundo da criança do Museu de Ciência e Tecnologia da PUCRS. 2012. 256 f. Dissertação (Mestrado em Interunidades em Ensino de Ciências) - Faculdade de Educação, Instituto de Física, Instituto de Química, Instituto de Biociências, USP, São Paulo.

LUCCHESE, M. M.; MACHADO, F. Trabalhando com a energia solar no ensino de física e ciências. In: MARRANGHELLO G. F.; LINDEMANN. R. H. (Org.). Ensino de Ciências na Região da Campanha: Contribuições na formação Acadêmico-profissional de professores de Química e Física. Itajaí: Casa Aberta, 2017.v. 1, p. 121-132.

MARTINS, I. P. Educação e Educação em Ciências. Aveiro: Universidade de Aveiro, 2002. $274 \mathrm{p}$.

MASSARANI, L.; NEVES, R. O olhar das crianças sobre uma exposição interativa. In: MASSARANI, L.; NEVES, R.; AMORIM, L. (Org.). Divulgação científica e museus de ciência: o olhar do visitante. Memórias do evento. Red de Popularización de la Ciencia y la Tecnología en América Latina y el Caribe - RedPOP. 1. ed., Rio de Janeiro: Museu da Vida, Casa de Oswaldo Cruz, Fiocruz, 2016, p. 63-72. Disponível em: $<$ http://www.museudavida.fiocruz.br/images/Publicacoes_Educacao/PDFs/Oolhardovisitante. pdf $>$. Acesso em: 27 jun. 2020.

MEDEIROS, A. A história e a física do fantasma de Pepper. Caderno Brasileiro de Ensino de Física, Florianópolis, v. 23, n. 3, p. 329-345, set. 2008. ISSN 2175-7941. Disponível em: $<$ https://www.periodicos.ufsc.br/index.php/fisica/article/view/5811/5801>. Acesso em: 22 jun. 2020. 
MIRANDA, A. C. DE B. et al. Alfabetização Ecológica e Formação de Conceitos na Educação Infantil por meio de atividades lúdicas. Investigações em Ensino de Ciências, Porto Alegre, v. 15, n. 1, p.181-200, mar. 2010.

MOREIRA, M. A. Teorias da Aprendizagem. São Paulo: EPU, 2011. 196p.

OLIVEIRA, M. K. Vygotsky e o processo de formação de conceitos. In: LA TEILLE, Y.; OLIVEIRA, M. K.; DANTAS, H. (Orgs.). Piaget, Vygotsky, Wallon: teorias psicogenéticas em discussão. São Paulo, SP: Summus, 1992. cap. 2.

OVIGLI, D. F. B., BERTUCCI, M. C. S. O ensino de Ciências nas séries iniciais e a formação do professor nas instituições públicas paulistas. In: SIMPÓSIO NACIONAL DE ENSINO DE CIÊNCIA E TECNOlOGIA, I, 2009, Ponta Grossa. Anais... Ponta Grossa. 2009. p. 1595-1612. Disponível em: <http://www.sinect.com.br/anais2009/>. Acesso em: 30 jul. 2020.

REGO, T. C. Vygotsky: uma perspectiva histórico cultural da educação. Petrópolis: Vozes, 2012. 100p.

STUDART, D. C. Museus e famílias: percepções e comportamentos de crianças e seus familiares em exposições para o público infantil. História, Ciências, Saúde - Manguinhos, v. 12 (suplemento), p. 55-77, 2005.

VYGOTSKY, L. S. O desenho na infância. In: Ensaios comentados: imaginação e criação na infância. Coleção Ensaios Comentados, São Paulo: Ática, p.105-128.

VYGOTSKY, L. S. Pensamento e Linguagem. 4. ed. São Paulo: Martins Fontes, 2008. 216 p.

VYGOTSKY, L. S. A Formação Social da Mente. 7. ed. São Paulo: Martins Fontes, 1991. $224 \mathrm{p}$.

ZUQUIERI, R. de C. B. O ensino de ciências na educação infantil: análise de práticas docentes na abordagem metodológica da pedagogia histórico-crítica. 2007. 200 f. Dissertação (Mestrado) - Faculdade de Ciências, Universidade Estadual Paulista, Bauru. Disponível em: $<$ http://hdl.handle.net/11449/90857>. 